\title{
READER-TEXT CONNECTION: REPORTING THE ENGAGEMENT OF HIGH SCHOOL STUDENTS WITH CULTURALLY RELEVANT TEXTS
}

\author{
Dannah Neriah L. Tan ${ }^{a}$, Ma. Joahna Mante-Estacio ${ }^{b}$ \\ ('dannah.tan@dlsu.edu.ph, bma.joahna.mante@dlsu.edu.ph) \\ De La Salle University \\ Manila, Philippines
}

\begin{abstract}
Maintaining students' engagement with reading texts that reflect their background knowledge has positive effect on their comprehension. Culturally relevant materials provide more equitable opportunities to students, in the sense that more of them can reap the benefits of being able to connect to the text (Christ \& Sharma, 2018). This article aims to identify the characteristics of texts, particularly those categorized as culturally relevant, which make them appropriate for a specific group of students. Three data gathering methods were used: ratings of texts, reflective journals, and discussion points during Literature Circles. Results indicate that the students participating in the study consider that similar experiences, relatability of the story in terms of feelings and motivation conveyed, actions of the characters, and possibility of experiencing the same event are the main factors that made reading texts culturally relevant to them. These text characteristics can guide classroom teachers, materials developers, and curriculum designers in choosing materials and preparing lessons for specific groups of students, as these underscore the importance of text relatability in building and keeping the students' reading interest and motivation.
\end{abstract}

Keywords: culturally relevant texts, reading comprehension, schema

DOI: http://dx.doi.org/10.15639/teflinjournal.v32i2/342-361

Readers use their background knowledge to predict various elements in the story, from the intended meanings of words and clauses, its message and theme, to the organization and structure of the story. Goodman (1982) states that this predictability is considerably aided by the degree of relevance of the text to the 
reader. When the reader's life experiences are more relevant to the experiences written in the text, the level of predictability and comprehension is easier as well.

Schema is a reader's long-term memory, which, when activated or instantiated, can generate text understanding. This background knowledge and previous experience directly affect how a reader comprehends the text (Ebe, 2011; Hu, 2019). There are three types of schema: content, formal, and linguistic. Content schema, the focus of the current study, is defined as knowledge relative to the content present in the text, which allows for better understanding of the text, especially if it contains an unfamiliar topic $(\mathrm{Hu}, 2019)$. Texts that have been manipulated to better reflect the content schema of readers have consistently shown to have a profound influence on reading comprehension. Examples include the studies of $\mathrm{Hu}$ (2019) and Wood (2021) where the participants showed superior reading performances on the material dealing with their own cultural background. These studies suggest that the reason is because texts with more familiar content and cultural heritages are easier to read and comprehend. This is especially important when exploring comprehension in the context of a second or foreign language, such as English as a second language (ESL).

Reading materials that directly tap into the cultural background knowledge of readers, or culturally relevant texts, are among the most effective materials to increase reading comprehension. Culturally relevant texts consist of content from which its readers can connect to, be it from their prior knowledge, backgrounds, or experiences (Christ \& Sharma, 2018; Ebe, 2011), which then makes reading relevant to them. In other words, they are texts that capitalize on students' cultural backgrounds (Scullin, 2014). This means that the diversity in students' cultures and background knowledge are considered assets instead of liabilities.

Freeman and Freeman (2004) emphasize that culturally relevant books and texts connect to students' lives, and not just their cultural heritage. In line with this, Goodman (1982) listed several factors to evaluate a text as culturally relevant beyond the ethnicity of the characters in the story. These include sociocultural-economic institutions, setting, chronological time, age and sex of characters, language variations represented in the text, theme, moral, and world view, and readers' experience with certain kinds of texts.

It is therefore logical to believe that reading culturally relevant texts relates positively with reading engagement. Increased reading engagement is particularly important, because it is one of the strongest predictors of reading achievement due to its direct relationship to the latter (Ebe, 2011). Moreover, 
culturally relevant texts help students negotiate their own identities. The active position that culturally relevant pedagogy puts students at the center not only affirms their natal cultural identity, but also helps develop their cultural competence (Christ \& Sharma, 2018; Freeman \& Freeman, 2004; McNealGirmai, 2010). With this, culturally relevant materials allow more students to connect to the text on a deeper level, therefore allowing more students to reap the benefits of this connection (Christ \& Sharma, 2018). Thus, the inclusion of culturally relevant texts in the reading curriculum is necessary. However, it is definitely not necessary that all the texts students read be culturally relevant after all, students need to be exposed to a variety of texts, multicultural or not. As Cartledge et al. (2016) point out, "reading materials and activities should never be limited to the child's background, but such literature may need to be stressed initially to obtain and retain the attention of the resistant and struggling beginning reader" (p. 418).

In various studies, it has been found that there are strong correlations between culturally relevant text (coupled with complementary teaching) and improved engagement and academic achievement. Culturally relevant texts have increased student interest, reading engagement, and achievement scores with various significance levels as compared to other required reading texts (Ebe, 2011; Marshall, 2011; Scullin, 2014). They are also shown to support improved literal, inferential, and critical understandings of texts (Christ \& Sharma, 2018). One reason for improved reading comprehension offered by McCullough (2008) was because there is "less room for misinterpretation" due to the student's prior knowledge aligning with the text, which is culturally relevant to it (p. 10). The relevance of the text allows for a seamless transition between text and the student's schema.

Ebe's (2011) study focuses on the relationship between cultural relevance of texts for English language learners (ELLs) and reading proficiency and comprehension. After observing that her Hong Kong students particularly had difficulty reading a story about pioneers in the 1800 s compared to other stories, Ebe (2011) observes that the problem may lie with the texts used for reading and assessment, and the need may be to further analyze these texts. As the participants of the study, nine third-grade ELLs from the Caribbean, Mexico, and Central America read two different stories orally, and these were digitally recorded. As part of miscue analysis, students were made to retell the complete text to analyze how the reader's comprehension of the text was during reading. These retellings and the digital recordings were subject to analysis using the In- 
depth Miscue Analysis Procedure of Goodman et al. (2005) to gain insights into how the students use different language cueing systems and learn information about how the students understood the story during (comprehending) and after (comprehension) their reading. Afterwards, the participants rated each story using the Cultural Relevance Rubric developed by Ebe (2011) based on Goodman's (1982) work. The higher the score of the story, the more culturally relevant it was for the student. The interesting finding in this study was the miscue analysis and retelling data, which suggested that the students' reading comprehension was greater when reading a story they identified as being more culturally relevant. For the story that they rated as being more culturally relevant, the students remembered more details with better accuracy, tending to provide lengthier and more detailed summaries of the story during retelling.

More recent studies on culturally relevant texts generally report similar positive results in using this type of materials in the classroom which therefore confirm the importance and value of culturally relevant texts. Culturally relevant texts enable students to interpret texts from various vantage points, thereby developing their critical thinking (Gao, 2020). These texts help learners become capable readers of materials suited to their grade levels even if they were performing below their expected level previously (Sharma \& Christ, 2017). In addition, these texts are read with high self-efficacy and engagement, which positively affected reading test scores (Livers, 2019). This type of texts also affirms students' identities (Kibler \& Chapman, 2018) and gives them power to become learning collaborators and "cultural experts" (Christ \& Cho, 2021, p.3) by teachers who are willing to share power in the classroom.

With these results, one obvious implication is the importance of adjusting the curriculum to accommodate the use of culturally relevant reading materials. The school where the participants in the current study are enrolled uses and adapts a foreign curriculum founded in 1970 by American pastors. The required reading materials set by the curriculum for grade 10 English are made up of novels or biographies of Christian personalities or missionaries, or fictional stories which emphasize Christian values. Therefore, the researchers argue that this curriculum fails to recognize the background knowledge and culturally relevant learning experiences of students (Roe, 2016). With the inclusion of culturally relevant texts in the curriculum through the intervention, this study gives students the chance to discover the fun and enjoyment of reading and understanding the themes behind it due to heightened engagement brought about by the texts' relevance to their own lives. It must be noted also that the school is 
starting its campaign to slowly rewrite the curriculum to fit modern-day needs and skills, so the goal of the current study is a natural fit towards this direction. To specify, the current study aims to identify the characteristics of texts which are perceived to be culturally relevant, which make them appropriate for a specific group of readers. Unlike previous studies that used only one or two data sources, the current study employs triangulation in data gathering (rubric scores, reflective journals, and Literature Circle discussion). The triangulation will disclose much data, which will also allow deeper analysis to identify characteristics that make texts culturally relevant to readers.

\section{METHOD}

\section{Participants}

The participants for this study were eight Grade 10 students, with an average age of 15 years old, studying at a private school in Quezon Province, Philippines at the time of the study. There were seven boys and one girl in this heterogeneous class, with five students of Filipino descent, two students of Chinese descent, and one student of Korean descent. This particular composition was not predetermined for any reason but was merely the actual composition of the class taught by the researchers. For the purpose of this research, the small size of the group was conducive to close examination of the process and results of the study so more detailed answers can be obtained during data collection. Validation and cross-verification of information through triangulation of data made up for the weaknesses and intrinsic biases that may arise as a result of the significantly smaller sample size of participants.

\section{Instruments}

\section{Reading Texts}

The participants read five reading texts prepared by the researchers, one text in every session. These include 'Fish Cheeks' by Amy Tan, 'Eleven' by Sandra Cisneros, 'Duffy's Jacket' by Bruce Coville, 'Dear Marsha' by Judie Angell, and 'The Summer of My $17^{\text {th }}$ Year' by H.O. Santos. All the five texts were selected primarily because their themes and dialogues were more familiar and relevant to the participants and their lives. 
All five reading texts are found to be within the independent reading level of the participants, based on Fry readability formula. 'Fish Cheeks' (1987) tackled the emotions teenagers go through when their home culture is presented to peers from a different cultural background, 'Duffy's Jacket' (2006) narrated the story of what happens to a particularly forgetful cousin, and 'Dear Marsha' (1989) told a story in terms of an exchange of letters between two ladies. Two coming-of-age stories were also present, namely 'Eleven' (1981), about the internal struggles of someone who just turned a year older, and 'The Summer of My $17^{\text {th }}$ Year' (n.d.), the story of a college-bound Filipina girl struggling with the initial signs of first love. All of these themes and their relevance to certain parts of the participants' lives were subsequently mentioned or touched on by the participants during their discussions within the Literature Circles.

Moreover, the characters in all the five stories are the same as or near to the age of the participants, who are in high school. The informal language variations represented in the stories (especially 'Duffy's Jacket', 'Dear Marsha', and 'Eleven') ranging from banter with family or friends to the careful yet emotional confiding to an older person were very similar to the way of expressing language as the participants do, as observed by the researchers in their daily interactions. The socio-cultural setting of 'Fish Cheeks', although written by a Chinese author, narrated a particular experience (being embarrassed by family members and/or their words and actions in front of peers) that each participant surely had experienced, again based on the stories they have previously told the researchers. Meanwhile, the morals and worldviews reflected in the words and actions of the main character in 'The Summer of My $17^{\text {th }}$ Year' are distinctly seen in the Filipino culture that the participants grew up in. All of the reading texts, except for 'Dear Marsha' (which was chosen largely due to the theme of teenage angst and the reasons behind it), fit the setting and chronological time of today's world where the participants are living in. These are further examples of how the reading texts could be more culturally relevant to the participants by covering different aspects of their prior knowledge.

\section{Cultural Relevance Rubric}

The Cultural Relevance Rubric used in this study was adapted from Ebe (2011), which is composed of eight questions that ask about the relevance of the plot, characters, and experiences described to the students' own experiences (see Table 2). Using a four-point Likert scale, respondents rated each question with 4 being the highest rating ('just like us') and 1 being the lowest rating ("not at all 
like us'). The results of the cultural relevance rating for each text partially inform the research question, which seeks to probe what specific characteristics of the text make it culturally relevant to the participants.

\section{Procedure}

Five class sessions were spent to gather data. Each session started with independent reading of the text, after which the participants individually evaluated the cultural relevance of the text using Ebe's (2011) rubric. Then the learners gathered in literature circles of four people each to further discuss the text. A thorough explanation of the roles of discussion facilitator, word finder, commentator and summarizer was given to the participants prior to the start of the data gathering. Specifically, one of the researchers explained to them what the four unique roles in the Literature Circle were and what specific tasks they should be doing in the literature circle should a particular role fall upon them. Questions and clarifications from the participants were also answered during this time to make sure that there were no lingering questions or confusions when literature circles started. After understanding the four unique roles each person would take inside the Literature Circle, the participants were given the choice to determine which participant would take on which role first - be it the discussion facilitator, word finder, commentator, and summarizer. The participant taking on each role was asked to take on a different role for the next session, which meant that each participant had already taken on every role possible after the fourth session. For the fifth and final session, participants were once again given the free will to assign among themselves the roles they would like to reprise the most.

One researcher took on the role of observer during each session of Literature Circles, with the main intention of observing the participants' body language and reactions to various things happening while the session was ongoing, as well as listening to their discussion and the ways they upheld their roles in the literature circles. When a remark or comment that is interesting or determined to be significant in writing the discussion of this action research was heard from the participants, it was immediately noted by the researcher either by writing it down on paper or typing it into a notes application on a computer. This not only helped the researcher to remember the details of the literature circle much later on, but also preserved the accuracy of what was uttered.

Aside from the researcher's personal observations and notes, further insight into the participants' thoughts about its implementation can be seen in their journals answering a specific journal prompt about the Literature Circle. These 
journals were assigned to the participants as homework to submit the next day, after completion of the abovementioned steps. Three prompts were answered in one journal entry. The first question changed with each session, while the other two were more or less the same throughout the five entries. For example, the following prompts were posed after the students read 'Fish Cheeks':

1. Do you think the main character's embarrassment is justified? Why or why not?

2. How would you evaluate the story in terms of how relatable it was to someone of your age? Could it relate to you or any part of your life?

3. How did you find the discussion of this text in your Literature Circle?

These prompts were displayed to the participants in a PowerPoint slide for them to copy on to their journal notebooks. The participants were allowed to ask clarificatory questions about the prompts before they left the class.

\section{Data Analysis}

The cultural relevance scores assigned by the participant for the reading texts were averaged per text to determine how the learners value specific characteristics of the texts. Observing and noting down the participants' utterances and their discussion of the text in their own literature circles is another rich source of data that informed the researchers about which characteristics of a text make it more culturally relevant for them. The learners' answers to the journal prompts were read several times and then put into codes and categories, which, together with the Literature Circle notes, were later transformed to themes that are grounded empirically and conceptually.

\section{FINDINGS AND DISCUSSION}

This study aims to identify the characteristics of texts which make them culturally relevant to readers. Using data from three sources, we present the results in themes that will show the various patterns that emerged from the analysis of the participants' responses to the cultural relevance rubric, journal entries, and comments made during the Literature Circle sessions. 


\section{Resemblance of the Context of the Text with Significant Life Events of the Readers}

The eight participants filled out a total of five Cultural Relevance Rubrics, one after each story was read. Table 1 shows the average cultural relevance scores given by the participants for each reading text.

Table 1. Cultural Relevance Means Per Text

\begin{tabular}{|c|c|c|c|c|c|}
\hline \multirow{2}{*}{$\begin{array}{c}\text { Student } \\
\text { Number }\end{array}$} & $\begin{array}{c}\mid c \\
\text { 'Fish } \\
\text { Cheeks' }\end{array}$ & 'Eleven' & $\begin{array}{c}\text { 'Duffy's } \\
\text { Jacket' }\end{array}$ & $\begin{array}{c}\text { 'Dear } \\
\text { Marsha' }\end{array}$ & $\begin{array}{c}\text { 'The } \\
\text { Summer of } \\
\text { My 17 } \\
\text { Year' }\end{array}$ \\
\hline 1 & 27 & 23 & 24 & 21 & 20 \\
\hline 2 & 15 & 21 & 17 & 14 & 20 \\
\hline 3 & 16 & 23 & 25 & 24 & 22 \\
\hline 4 & 15 & 16 & 18 & 10 & 15 \\
\hline 5 & 18 & 18 & 17 & 15 & 19 \\
\hline 6 & 18 & 17 & 14 & 16 & 20 \\
\hline 7 & 18 & 12 & 21 & 15 & 19 \\
\hline 8 & 22 & 17 & 21 & 16 & 25 \\
\hline Mean Score & $\mathbf{1 8 . 6 3}$ & $\mathbf{1 8 . 3 8}$ & $\mathbf{1 9 . 6 3}$ & $\mathbf{1 6 . 3 8}$ & $\mathbf{2 0 . 0 0}$ \\
\hline
\end{tabular}

Among the five reading texts, 'The Summer of My $17^{\text {th }}$ Year' obtained the highest mean for cultural relevance. Based on the criteria set by Goodman (1982), the aspects of socio-cultural-economic institutions, setting, chronological time, age and sex of characters, language variations, and reader experience with this kind of reading text can be found in the highest amounts in 'Summer'. Given the participants' penchant for exactness in rating cultural relevance compared to their own experiences, one factor that caused 'Summer' to have the highest rating among the reading texts was that the participants' current city of residence at the time was directly mentioned in the story. Aside from this, the biggest factor that helped boost cultural relevance was the theme of teen romance, which was very relevant to readers at their current age. The timelessness of the theme meant that the characters would be like them, that the events of the story could take place 
Tan \& Mante-Estacio, Students' Engagement with Culturally Relevant Texts 351

this year, and that they would have already had a similar experience - all of which are questions in the cultural relevance rubric.

Table 1 presents the average rating for each text; however, it is also interesting to see more details that will clarify how the average scores were arrived at. This can be done by looking at the scores per question asked in the rubric.

Table 2. Cultural Relevance Means Across Questions

\begin{tabular}{|c|c|c|c|c|c|c|}
\hline Rubric Questions & 这 & 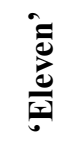 & $\sum_{\substack{0 \\
0}}^{\infty}$ & 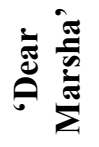 & 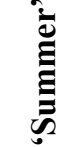 & $\sum^{E}$ \\
\hline $\begin{array}{l}\text { 1. Are the characters in the } \\
\text { story like you and your } \\
\text { family? }\end{array}$ & 1.75 & 2.00 & 1.88 & 1.88 & 1.38 & 1.778 \\
\hline $\begin{array}{l}\text { 2. Have you ever lived in } \\
\text { or visited places like } \\
\text { those in the story? }\end{array}$ & 2.88 & 3.50 & 2.63 & 2.88 & 3.25 & 3.028 \\
\hline $\begin{array}{l}\text { 3. Could this story take } \\
\text { place this year? }\end{array}$ & 3.00 & 2.63 & 2.75 & 1.38 & 2.88 & 2.528 \\
\hline $\begin{array}{l}\text { 4. How close do you think } \\
\text { the main characters are } \\
\text { to you in age? }\end{array}$ & 3.25 & 2.5 & 3.75 & 3.00 & 3.13 & 3.126 \\
\hline $\begin{array}{l}\text { 5. Does the story have } \\
\text { main characters who are } \\
\text { boys (for boy readers)? } \\
\text { Girls (for girl readers)? }\end{array}$ & 3.00 & 1.88 & 3.50 & 1.88 & 3.63 & 2.778 \\
\hline $\begin{array}{l}\text { 6. Do the characters talk } \\
\text { like you and your } \\
\text { family? }\end{array}$ & 1.75 & 2.00 & 1.63 & 1.25 & 1.63 & 1.652 \\
\hline $\begin{array}{l}\text { 7. How often do you read } \\
\text { stories like this one? }\end{array}$ & 1.63 & 1.63 & 2.00 & 2.13 & 2.13 & 1.904 \\
\hline $\begin{array}{l}\text { 8. Have you ever had an } \\
\text { experience like one } \\
\text { described in the story? }\end{array}$ & 2.13 & 2.25 & 1.50 & 1.75 & 1.75 & 1.876 \\
\hline
\end{tabular}


It can be seen in Table 2 that the cultural relevance rating mean was highest across the five texts (3.126) for the fourth question followed by the second question (3.028). These results imply that similarities in context (i.e. setting) and in traits between the story and the reader are the main considerations in judging the cultural relevance of a reading material. It is interesting to point out that ' $F$ ish Cheeks' and 'Duffy's Jacket' received higher scores than 'Summer' in this question. In fact, in six out of the eight questions, there were other materials rated higher than this text. It would imply that while in general 'Summer' is considered the most culturally-relevant, there are other culturally-relevant traits that are more prominent in the other texts based on the participants' evaluation.

Interestingly, the lowest cumulative score was observed for question 6 . This may seem a little strange, given that the character self-thoughts and dialogues used in stories like 'Fish Cheeks', 'Duffy's Jacket', and 'The Summer of My $17^{\text {th }}$ Year' were similar to the participants' manner of talking, as well as the words they utter on a daily basis (as constantly observed by the researcher). However, during the Literature Circle, the participants explained that they scored that question based on the content of what the characters said in the story. In other words, the low ratings given for the way the characters talked was not because the manner of their speaking was different from theirs, but rather because they felt that what the characters were saying were not similar to what they themselves would say. This shows that for a story to be relevant to a certain group of students, having teenagers as main characters is not enough, but what the characters talk about in the story should somehow correspond to or resemble what they say or talk about in their everyday lives (Stewart, 2017).

For question 7, even for the stories they expressed enjoyment in reading and discussing, the participants rated each story relatively low, with the lowest being 1.63 ('Fish Cheeks' and 'Eleven') and the highest being 2.13 out of 4.00 ('Dear Marsha' and 'The Summer of My $17^{\text {th }}$ Year'). This is because they do not encounter modern reading texts like these in school as shared during the Literature Circle.

Question 8 asked about the extent to which participants have had experiences similar to the story, and the responses were varied. One instance was 'Duffy's Jacket', which received the lowest cumulative rating of 1.50. While participants understood and enjoyed reading the story, they also expressed later in their journals that their parents will most likely never leave them alone with a younger sibling in an unfamiliar area, as how it was in the story. The differences 
between story happenings and reality which they found were also reflected in their ratings for rubric question 8 , leading to a lower rating.

\section{Relatability with Characters' Actions and Feelings}

After reading each story, the participants answered a journal prompt asking: "How would you evaluate the story in terms of how relatable it was to someone your age? Could it relate to you or any part of your life?" Their responses were often directed at whether the text was relatable or not, or which parts of it could be further discussed. Aside from this, the participants' responses also indicated which specific characteristics of the text made a text more relevant or less relevant for them.

First, the participants found the story as a whole to be relevant if the feelings of the characters were the same or similar to the ones they were currently feeling. For instance, participant 4 did not find 'Eleven' interesting because he had never felt as emotional in school as the character did, and while he had liked a girl before, he stated that he did not relate to the main character in 'Summer' because the extent of his liking her did not reach the same heights. On the other hand, for 'Fish Cheeks', participant 1 said that "the writer did a great job in describing the deep, intricate, and hidden feelings of teens," suggesting that he was commending the writing for being relatable to their own teenage emotions.

Next, participants also found the story to be relevant if the actions of the characters were also something that they would do. One good example is what participant 3 wrote about 'Eleven', when she said that "there are certain actions I still do that are similar to the story. Such actions like crying like a three year old, to feel comfort from my mom like I was five, and stupid things I do, which is part of me that's still ten." Aside from the parallel experiences mentioned, it is also observed that the participant wrote in a similar style as how the author did in the story, showing the lasting impact of the relevance found in the story. Experiences pertaining to the opposite were also expressed by a number of participants who found themselves not relating to 'Fish Cheeks' very much, like participants 6 and 7 who stated that they love their parents and family, and would not be ashamed of them "even when they do very goofy and weird things."

The most obvious point of a story's relevance that the participants identified was when there were incidents that mirror or are possibly very similar to what they experienced themselves, making it more relatable. After all, students are considered equipped with adequate and existing content schema if they have recently experienced similar events in their own lives (Pearson-Casanave, 1984). 
Regardless of the cultural relevance rating they gave to each text, the majority of the participants regularly expressed that the text was relatable in various ways during each instance of journaling. For example, participant 6 , in writing for 'The Summer of My $17^{\text {th }}$ Year', said that the story was really relatable because it was written for people their age, who often seek a relationship without thought for future consequences. Sometimes, participants realized this point of relevance only after having read and discussed the text, as is the case with participant 6 for 'Eleven'. He mentioned that while reading, he had never thought about how one cannot change in character as he ages, but then he realized that people like him can actually relate to Rachel's situation without being aware of it yet. This actually showed the participant's recognition of the author's ability to correctly identify a particular stage in their life, and how comprehension was ongoing in the participant even after he has finished reading the text (Duke \& Pearson, 2009; Goodman, 1982).

Similar examples can be seen from the journals for 'Duffy's Jacket', which was a text that they enjoyed reading and discussing more compared to the other texts. In spite of this, participant 7 said that for someone like Duffy who is already 15 and has experienced forgetting a lot of times, he should have already felt the consequences of his actions enough to learn, therefore making the character a bit out of touch with what he imagined to be reality. Another example is for 'Eleven', where participant 7 expressed, "To me, the part that really related to me was when the teacher refused to believe her. It really made sense to me how she felt bad because I've been in that position a lot of times and it was very similar to what happened in the story."

It is also significant to note that while participants seemed to rate the stories based on exactness in the cultural relevance rubric, which led to ratings lower than expected, they also showed a surprising degree of leniency and understanding in their journals. Many excerpts of their journals showed that while they may not share the same experiences or backgrounds as the characters, they still found the story relevant to people like them. For example, for 'Fish Cheeks', participant 3 mentioned that while he does not get embarrassed of his parents and their comments during visitor dinners as how the character did, he still finds the story relatable. Participant 5 expressed that "it can't really relate to my life, but I think there are a lot who can relate with the story who are around our age" after reading 'The Summer of My $17^{\text {th }}$ Year'. This shows that while the plot of the story did not resound with his own background, he recognizes that this is a common theme among his peers, therefore still making it more relatable 
for them than the usual texts they read for school. Various reflections like these showed that as they read and reflected on the text, they were also exposed to new areas of possible conversation that add new things to their knowledge as national and global citizens (Chin \& Thomas, 2010).

Even for 'Dear Marsha', which was rated the least culturally relevant text, there were many expressions of relevance present in the text. Participant 7 mentioned that while the happenings in 'Dear Marsha' would not be very possible in today's digital age, "the story itself... (disregarding the letters) was pretty relatable." This was because the participant remembered one key conflict in the story, where the character was accused of stealing and wanted to stay with Anne-Marie as a result. Participants 4 and 8 concurred, relating the story's events to the online chatting of today by adding that "anyone can disguise as anything because they don't have to meet up in real life." This shows that the plot of the text or the events present in it do not have to exactly match what the participants have experienced to be relevant - instead, it is found to be relevant enough if it can mirror events in today's world and their lives.

\section{Connection with Characters' Values and Motivations}

Tables 1 and 2 show 'Dear Marsha' as the least culturally relevant text, and it was quite easy to see why. None of the participants have ever been pen pals with someone as how the characters were in the story, and only one out of all the participants has ever written and sent an actual letter. For them, letter-writing is already something of the past, something they would not have known about if not for their English classes. When one of the participants commented that "the only letters we have ever written in our lives were those for our English class," it led to instant agreement from the rest of the participants. Thus, they could not be expected to relate with the letter-writing and all its nuances present in the text - the most they could do was to connect it to the chatting and messaging of today, which they were able to do.

Another characteristic of the text which lessened its relevance for them was the adult main character's behavior, which some of them commented as unlikely, given that the character should have been presented to be more mature. The participants often held this character, Anne-Marie, to their own ideals of what adults are like, saying things about her like "she should have known better than to do that (lead her on)." This was consistent with the second lowest-rated rubric question, showing that they did not find this character similar to the adults they know and their perceived actions. 
For 'Eleven', all the participants except the female participant found the main character to be overly dramatic, which was a source of comic relief for them in their Literature Circles. Gender would seem to play a major role here, as the participants were predominantly male while the main character was a female. One thing that they were all able to find relevant was that the main character being accused of something she did not do, although they also agreed that their reactions would have been different from the main character's.

'Fish Cheeks' was the first story they read for this study, and while the researchers were expecting the participants to relate well to the plot of the text, their responses were not definitive. During their discussion, they found the main character's reaction to her crush being at their family home understandable, but not the way she treated her parents afterward for not being American enough. It was in the discussion of this text that the cultural aspect was most obvious. The participants widely could not relate to the main character's thoughts because for them, they would still love their family and not be ashamed of them even if cultural differences were shown in front of their peers. The level of cultural relevance (or lack thereof) for 'Fish Cheeks' illustrated the difference between the author's culture and the participants' own cultures.

From these examples, it can be deduced that the participants found it difficult to relate and understand parts of texts where the characters' values, thoughts, and reasons behind their actions are different or quite distant from what they perceive as correct or reasonable. Relevance of texts seems to be based on how the readers could tolerate and give justification to the characters' motivations and values. When this happens, readers tend to react positively to the reading materials (Ebe, 2012; Sailors \& Kaambankadzanja, 2017; Sharma \& Christ, 2017; Stewart, 2017)

The participants were most active and lively while in their Literature Circles for 'Duffy's Jacket'. Aside from the fact that it was considered the most fun to read for the participants, the theme of forgetfulness was something that resounded loud and clear with them, because the majority of them were also habitually forgetful, as observed by one of the researchers. They also could relate with and enjoyed certain youth expressions uttered by the main characters, such as calling each other 'stupid', which led to a few rounds of imaginative roleplaying in the Literature Circles.

While they immensely enjoyed the story, the fantasy elements present in it meant a lack of actual relevance for the participants. Certain participants said quite frankly that the presence of elements like the monster was "puzzling", but 
they appreciated the story anyway. One point the participants' discussion also focused on was the behavior of the mothers of the main characters, which again showed a difference in cultures. They reasoned that "our mothers would never dare leave us alone in an unfamiliar place", or in situations like those described in the story, so some events of the story also lost relevance for them.

'The Summer of My $17^{\text {th }}$ Year' was not only the highest-rated reading text for cultural relevance, but also the last reading text of this research. As such, by this point, the participants had already learned how to successfully bridge the disparity between the events in the story and their actual experiences to properly discuss similarities and differences.

One sign that there was a higher level of relevance found for 'Summer' was the discussion in a Literature Circle session where the female participant was present. Almost immediately, the members of the group started pointing out the fact that there was an uncanny similarity between the events of the story and their female classmate. "Young teenage female living in the province? Check. Guy best friend? Check. Hot, older friend of the best friend coming from abroad? Hmmm, check! Should I mention that she had a crush on him too?" These remarks immediately made by one of the members of this particular Literature Circle caught everyone's attention and immediately led to a back-and-forth discussion on the differences between males and females. This meant that while they did not share the same experience as the main characters, the participants found it relevant enough to happen in the present day to immediately connect it with their classmate's experience.

Other members of both Literature Circles also argued about what the character's motivations were for a certain action or decision, indicating that they were also able to relate to the characters from different points of view. This was the focus of the other Literature Circle, which was arguing about whether the male protagonist's actions led the female protagonist on or not. Heated, albeit friendly, exchanges starting with "Yes, it was totally leading her on because..." and "You can't say that it's leading you on because..." showed their willingness to debate this point based on their own perceptions of the story, and each participant was observed to be actively sharing their own opinions on the topic. By this point, the participants' active and unforced participation could be observed clearly, and this is a characteristic of students showing an increase not only in learning but also in engagement with the text and each other. This is a result of students being given more opportunities to discuss their own culture 
and background knowledge, consistent with Roe's (2016) results in her own case study.

\section{CONCLUSIONS}

This study looked at which characteristics of a text made it more culturally relevant for the participants. From the results of the cultural relevance rubric ratings, the journal entries written, and the researcher's notes of the participants' reactions, it was found that the level of realism in a story was something they often looked for. The content of what the text characters talk about, instead of simply the way they talk, was a significant factor for the participants in rating something high in cultural relevance.

In rating the five reading texts for their cultural relevance, the participants relied heavily on their own backgrounds and experiences, often to the point of exactness. This resulted in the reading texts being rated lower than expected, even if appreciation for the texts was shown by the participants. On the other hand, the participants showed a positive response towards implementation of the literature circles; the responses of which were noted not only from their oral feedback observed and noted by the researcher, but also from their journal entries. Participants expressed enjoyment of the collaboration and discussion that happened inside their literature circles. This resulted in a better understanding of the reading text in general compared to if participants were to read the text on their own as usual.

The aforementioned results confirm that texts considered to be more culturally relevant are those that tap into their existing background or previous firsthand experiences. It does not mean that the events of the story have to mirror what happens in their lives - rather, it should be realistic enough that something similar has happened or can also happen to them, either in part or in whole. Relevance was also found if the motivations or intentions behind a character's action(s) are factors which can be personally understood by the reader.

Connected to this, it is worth noting that almost all of the participants' answers focused on the relevance of the text to their own backgrounds and experiences, but with the cultural component absent. This is consistent with what Freeman and Freeman (2004) emphasize, which is that culturally relevant texts connect to students' lives, and not just their cultural heritage. The researchers believe that the results of this study simply show that there remains a lot to be discussed and desired in the area of cultural relevance itself. 
Also, the results from the current study imply that the use of more culturally relevant texts is a factor that may be considered by teachers whose students are expressing disinterest or disconnect with their current reading texts. In the case of the participants in this study, although the texts were not rated to be completely culturally relevant to them, the level of relevance found in the texts was still significantly higher than the current reading texts required in the curriculum of the school where the participants study, which were mostly from the early 1900 s. This resulted in an unprecedented level of focus observed by the researchers from the participants during independent reading and self-stimulated engagement in text discussion, which are always desirable results for teachers of English and reading in general.

Further study in this area could explore better ways to identify what cultural relevance would be like for a different class or group of students. Another worthy goal is to see if informative texts could also be culturally relevant to readers. A third interesting topic in this area is to find out if the notion of culturally relevant texts among students changes across ages and grade levels. Lastly, a study that will directly assess students' reading comprehension of culturally relevant texts and those which are not may be conducted.

\section{REFERENCES}

Cartledge, G., Keesey, S., Bennett, J., Ramnath, R. \& Council III, M. (2016). Culturally relevant literature: What matters most to primary-age urban learners. Reading \& Writing Quarterly, 32(5), 399-426. https://doi.org/10.1080/10573569.2014.955225

Chin, E. L., \& Thomas, P. L. (2010). Reading nation and world: Cultivating culturally and critically reflexive readers. The English Journal, 100(1), 108112. https://www.jstor.org/stable/20787702

Christ, T., \& Sharma, S. A. (2018). Searching for mirrors: Preservice teachers' journey toward more culturally relevant pedagogy. Reading Horizons: A Journal of Literacy and Language Arts, 57(1), 55-73. https://scholarworks.wmich.edu/reading_horizons/vol57/iss1/5

Christ, T., \& Cho, H. (2021). Sharing power in read-alouds with emergent bilingual students. The Reading Teacher, $0(0)$, 1-10. https://doi.org/10.1002/trtr.2021 
360 TEFLIN Journal, Volume 32, Number 2, July 2021

Duke, N. K., \& Pearson, P. (2009). Effective practices for developing reading comprehension. Journal of Education, 189(1-2), 107-122. https://doi.org/10.1177/0022057409189001-208

Ebe, A. (2011). Culturally relevant texts and reading assessment for English language learners. Reading Horizons, 50(3), 193-210. https://scholarworks.wmich.edu/reading horizons/vol50/iss $3 / 5$

Ebe, A. E. (2012). Supporting the reading development of middle school English language learners through culturally relevant texts. Reading \& Writing Quarterly, 28(2), 179-198. https://doi.org/10.1080/ 10573569.2012.651078

Freeman, Y., \& Freeman, D. (2004). Connecting students to culturally relevant texts. Talking Points, 15(2), 7-11. https://library.ncte.org/journals/tp/ issues/v15-2/2973

Gao, J. (2020). Culturally relevant pedagogy in teaching proficiency through reading and storytelling. Chinese Language Teaching Methodology and Technology, $3(2)$, 63-70. https://engagedscholarship.csuohio.edu/cltmt/vol3/iss2/5

Goodman. Y. M. (1982). Retellings of literature and the comprehension process. Theory Into Practice, 21(4), 301-307. https://doi.org/10.1080/00405848209543022

Goodman, Y.M., Watson, D. J., \& Burke, C. L. (2005). Reading miscue inventory: From evaluation to instruction $\left(4^{\text {th }}\right.$ ed.). Richard C. Owen Publishers.

$\mathrm{Hu}$, J. (2019). The influence of content schema on L2 learners' reading comprehension: Evidence from Chinese learners of English. English Literature and Language Review, 5(3), 31-37. https://doi.org/10.32861/ellr.53.31.37

Kibler, K., \& Chapman, L. A. (2018). Six tips for using culturally relevant texts in diverse classrooms. The Reading Teacher, 72(6), 741-744. https://doi.org/10.1002/trtr.17

Livers, D. (2019). The impact of culturally relevant texts on $5^{\text {th }}$ grade reading comprehension (Publication Number 22583733) [Master's thesis, Spalding University]. ProQuest Dissertations and Theses Global.

Marshall, J. (2011). Enhancing reading interest, motivation, and achievement through a culturally relevant text (Publication Number 3469688) [Doctoral dissertation, Walden University, Minneapolis, Minnesota, USA]. ProQuest Dissertations and Theses Global. 
Tan \& Mante-Estacio, Students' Engagement with Culturally Relevant Texts 361

McCullough, R. (2008). Untapped cultural support: The influence of culturally bound prior knowledge on comprehension performance. Reading Horizons, 49(1). https://scholarworks.wmich.edu/reading_horizons/vol49/iss1/3/

McNeal-Girmai, E. A. (2010). "This is our life. We can't drive home." An analysis of culturally relevant pedagogy as perceived by elementary teachers, students and families in an urban charter school (Publication Number 3498400) [Doctoral dissertation, Loyola Marymount University, Los Angeles, California, USA]. ProQuest Dissertations and Theses Global.

Pearson-Casanave, C. R. (1984). Communicative pre-reading activities: Schema theory in action. TESOL Quarterly, 18(2), 334-336. https://www.jstor.org/stable/pdf/3586700.pdf

Roe, K. (2016). Cultural relevance in an English language learners' classroom: A qualitative case study [Doctoral dissertation, Walden University, Minneapolis, Minnesota, USA]. https://scholarworks.waldenu.edu/ dissertations $/ 2877$

Sailors, M., \& Kaambankadzanja, D. (2017). Developing a culture of readers: Complementary materials that engage. The Reading Teacher, 71(2), 199208. https://doi.org/10.1002/trtr.1589

Scullin, B. L. (2014). "Being true”; How African American adolescent male students participate in a culturally relevant literature-based reading curriculum [Doctoral dissertation, Kent State University, Kent, Ohio, USA.] Ohio LINK Electronic Theses and Dissertations Center. https://etd.ohiolink.edu/

apexprod/rws_etd/send_file/send?accession=kent1416441802\&disposition $=$ inline

Sharma, S. A., \& Christ, T. (2017). Five steps toward successful culturally relevant text selection and integration. The Reading Teacher, 71(3), 295307. https://doi.org/10.1002/trtr.1623

Stewart, M. A. (2017). "I love this book because that's like me!" A multilingual refugee/adolescent girl responds from her homeplace. International Multilingual Research Journal, 11(4), 239-254. https://doi.org/10.1080/19313152.2016.1246900

Wood, P. J. (2021). Changing the narrative: The effect of culturally relevant teaching to improve reading comprehension and engagement among African American males in middle school [Thesis, Rowan University, Glassboro, New Jersey, USA]. Rowan Digital Works Theses and Dissertations. https://rdw.rowan.edu/etd/2857 